\title{
Advocating Gender Compatibility for Sustainable Social Development
}

\author{
Vera Idaresit Akpan* and Udodirim Angela Igwe \\ Department of Adult and Continuing Education, Michael Okpara University of Agriculture, Nigeria
}

Submission: April 11, 2018; Published: May 01, 2018

*Corresponding author: Vera Idaresit Akpan, Department of Adult and Continuing Education, Michael Okpara University of Agriculture, Umudike, Abia State, Nigeria, Email: nwanidaresit@gmail.com

\begin{abstract}
This paper sets out to discuss how gender compatibility could bring about sustainable social development for the benefit of all. The meaning of gender and sex were distinguished from each other, while gender compatibility was seen as a concept which combines gender contentedness with responsiveness to ensure complimentary and harmonious existence. Gender compatibility creates the atmosphere for sustainable social development and its attendant benefits to the people. The implications of the discussions were that gender stereotypes where derogatory and antisocial, which could kill talents, encourage lousiness, oppression, self conceit and arrogance. Gender roles were considered socio-cultural, subject to change with time and therefore should not be held sacrosanct. It was recommended that gender stereotypes be erased from people's minds and gender roles considered complimentary rather than defamatory. While individuals, irrespective of their gender should be allowed to play roles according to their natural abilities, talents and callings, since no gender is superior to the other. Social development is about improving the well-being of every individual in the society and this requires the removal of barriers so that all citizens can reach their full potentials with confidence and dignity.
\end{abstract}

\section{Introduction}

Apart from the different biological features which make one a female and the other a male, both live in the same planet and are subject to the same human conditions. In other words females and males have the same human make-ups, tendencies and capacities. It is mind bugging to see that one of the two (female and male), in all things and most times claims superiority over the other. To say the obvious, the society is gender bias as they tend to give more credence to men when it comes to power, fame and wealth. More often the women are seen perspiring behind the scene to show case the man and there is the saying that "behind every successful man there is a woman." If the woman can stand behind working hard to make him successful, she would double the success if she is given the same support given to the man. Rightly put, if women and men are given equal opportunities to function according to abilities, talents and desires the society would benefit economically, financially, educationally and all these will build and sustain the social development of our communities. The issue at hand is not comparing the woman and the man but to see them as two sides of one coin, where the coin is the society. As in a coin, when the appearance of one side is marred or defaced the coin can no longer be accepted as a legal tender, so it is in a society where one gender is marred.

Equal opportunities can only be made available when issues on gender roles and stereotypes are laid to rest while gender typicality and contentedness are well handled. The aim of this discussion is to advocate gender compatibility as a means of removing the divide that makes one gender inferior to the other so that the efforts of all and sundry will be optimal for sustainable social development. This paper intends to bring this view to bear under the following sub headings:

a) Defining gender

b) Gender roles and stereotypes

c) Gender typicality and contentedness

d) Gender compatibility and social development

\section{Defining Gender}

The word gender once mentioned in some circles often connote issues that border on women. This notion is opposed by Ibe [1], who asserts that "gender is not women's issue: it is people's issue." Mlama [2], define gender as socially determined roles and relations between males and females or a socio cultural classification of women and men. The definition of Kanno [3]. On gender is more elaborate. They define it to mean socially or culturally constructed characteristics, rules and qualities which different societies assign to males and females varying from one society to another and at different times in history. While Merriam [4] in their dictionary defined gender as the sex of individuals that determine whether they are male or female based on their structures and reproductive organs. In other words gender refers to the sex of an individual, either female 
or male. The world health organization (WHO) also sees gender as the socially constructed characteristics of women and men. This means that it the society that determines norms, roles and relationships between women and men. This social construct varies from society to society and can be changed. For instance in some cultures it is the men who pound yam while it is a taboo in some other. Again in some cultures in Nigeria, during the funfair that accompany traditional marriage formalities, it is the bride who seeks for the groom whereas some others within the same country have the groom search for his bride. This is to explain that gender concerns are not independent of the traditional institutions and cultures within which they function.

Sex is a predetermining factor for gender; it generally refers to biological differences between females and males, which are usually anatomical and physiological. This explains why the female and male genitalia, both internal and external are different. In addition to this, the levels and types of hormones present in male and female bodies are different Newman 2004. This is to say that the female and male are different physiologically and biologically. This study seeks to infer that the difference in gender should be harnessed for social development.

Simply put, sex refers to biological differences which have to do with chromosomes, hormonal profiles, internal and external sex organs while gender describes the characteristics that a society or culture portrays as masculine or feminine. Irrespective of one's sex every one whether girl or boy / woman or man is unique in his/her own way, none is better than the other and none is inferior to the other. In other words both of them are equal to each other though they are not the same in physical and biological roles as endowed by nature; Bloom [5] affirms that "equality does not mean sameness". In every sense a girl or woman is not the same with a boy or man, they are different biologically and to this end they have different roles to play in procreation and human existence which are the unalterable designs of nature. At the same time they are equal because they possess the same human capacity for empathy, aptness, ingenuity and agility. This is what gives credence to gender roles and stereotypes.

\section{Gender roles and stereotypes}

In this context, roles are socially assigned behavior pattern or characteristics doled out by the society to individuals. Gender roles therefore, refer to the characteristics and behaviors that different cultures attribute to the female and male sexes Nobelius [6]. When people are born as either male or female, they are taught appropriate norms and behaviors-including how they should interact with others of the same or opposite sex within households, communities and work places (WHO). The difference in females and males are spelt out by their natural or biological roles and the socio-cultural roles. Sex roles are biological and naturally designed but gender roles or dynamics are designed and enforced by the culture of the society. For instance the role of women and men in reproduction is designed by nature whereas the roles of women as cooks and house-keepers are gender roles which are formulations from the society which gives the base for gender stereotypes. Gender stereotypes are over-generalizations about the characteristics of an entire group based on gender for example when it is said that all women are feeble minded or that all men are cruel. These kinds of overgeneralizations are made because of existing inherent gender difference found in males and females; unfortunately they lead to gender bias and discrimination.

The excerpt from a trade publication called Earnshaw's Infants' Department, published in 1918 shows that gender roles and stereotypes are subject to change and differ from society to society. «The generally accepted rule is pink for the boys and blue for the girls. The reason is that pink, being a more decided and stronger color, is more suitable for the boy, while blue, which is more delicate and dainty, is prettier for the girl.» Retrieved on line https://www.glaad.org/reference/transgender. The reverse has been the case one hundred (100) years later, it is rare to find a baby boy dressed in pink today. Gender roles and stereotypes though unstable in application are not needed in a society that is yet to be socially developed. They have so much adverse effect on the social life of the society. Gender roles and stereotypes are derogatory. They tend to slight the personality of the female folk. They are antisocial because tend to narrow the path of human relations by expressing inequality among females and males. This kills talents because what a woman would have done as a result of talents is being relegated because she has been convinced she cannot do it because it can only be accomplished by men. Gender roles encourage lousiness and indiscipline especially among the males. They become victims of alcoholism, violence and other vices so easily more than the females because they are often at liberty than the females. Gender roles encourage oppression of the women. The men are often stationed as lords while every weight at home and in the society is laid on the woman, yet the man dominates her sometimes without empathy. They encourage self conceit and arrogance because men will try to be men even when they know that their stamina cannot carry them. They will often wear a false appearance in order to appear strong.

They society seem to have a fixed measure for anyone to be truly a female or male apart from the biological yardstick that is given naturally. What this means that at birth one's sex may be determined but if the person is not behaving to fit into the role typical of that gender as expected by the society, then the problem of gender typicality will surface.

\section{Problems of gender typicality}

Gender typicality is being exactly what the society has marked out for your gender. It is exhibiting the essential characteristics of one's gender as laid down by the society. Simply put, it is an established form of gender roles and stereotypes. It breeds antisocial peer relationships: children tend to queue in so easily into laid down roles of gender by the society. If they find any one not 
exhibiting within the confines of this social set-up they quickly abhor such a person. Those who live exactly by the norm are said to be gender typical. Oberle [7] found that possession of empathy was inversely related to peer acceptance of boys. These findings can possibly be explained by prior research which has shown that children and adolescents who exhibit gender atypical behavior often experience peer relationship problems such as rejection Young [8]. This is likely the effect of gender stereotypes, which suggest that males are expected to possess assertive skills and traits, whereas females are expected to exhibit communal traits like concern for others, emotional empathy and others like it Eagly [9]. Given these gender stereotypes, it is possible that boys who possess high levels of social-emotional skills such as empathy could yield negative outcomes, such as peer rejection, if those skills are deemed "atypical" for boys Petersen [10].

Gives false impression of one's self: gender typicality seem to qualify people as real or fake. In explaining this, Nobelius [6] says what it means to be a 'real man' in any culture requires male sex plus what our various cultures define as masculine characteristics and behaviors (real man = male sex+masculine social roles), likewise a 'real woman' needs female sex and feminine characteristics (real woman $=$ female sex + feminine social roles). In other words you are a real man or woman when you align with the roles assigned by the society. This could make the males over confident and the females get withdrawn to the backyard because they feel that is where they belong. Sometimes there are conflicts in the display of natural biological functions for instance when a male possesses a female voice and vice versa. This situation could show up in other areas of growth development and because one wants to stick to already laid done roles for gender, there will be the tendency to try to put up those traits that may not have been there in order to satisfy the assumptions of the society. An example is a man who has a natural calm or docile disposition trying to look assertive before the wife and the extended family so that he will be "a real man".

Jewell [11] observed that gender typicality which is an extension of gender roles and stereotypes, relates to positive and negative peer relations in preadolescence. Petersen [10] observe that gender typicality both affects and is affected by relationships with others. For instance by the age of 6 children, know and endorse gender stereotypes regarding personality (e.g. boys are loud and active; girls are quiet and docile), which influences them to view gender atypical behavior negatively and avoid peers who break gender rules. This is an instance where gender stereotypes mar relationships, breed hatred and violence. Researchers have also observed that Children who are low in gender typicality are more likely to have less of a sense of self-worth, more likely to be perceived as anxious or depressed, and are at greater risk for suicide compared to children who are high in gender typicality Carver [10]; Russell [13]; Yunger 2004. These findings highlight that high level of gender typicality can lead to high self esteem which is required for optimum self realization and positive contribution to social development. It builds platforms for pride and indiscipline: The assertions that men are stronger or can do better than the females make some of them to be proud and arrogant. Creating a feeling that one is superior to the other could lead to pride, and in subordination.

\section{Gender compatibility}

Gender compatibility is a relationship of mutual benefit between females and males such that one compliments the other and neither can do without the other. In every sense a girl or woman is not the same with a boy or man, they are different biologically and to this end they have different complimentary roles to play in procreation and human existence which are the unalterable designs of nature. They function symbiotically to achieve the objectives of communal living and for a continual and meaningful existence of the human world. Gender compatibility can only be achieved in a society that is gender responsive. Mlama et al. [2]. Define gender responsiveness as taking action to correct gender bias and discrimination so as to ensure gender equality and equity. They went ahead to define the terms; gender discrimination and bias means denying opportunities and rights or giving preferential treatment to individuals on the basis of their sex.

Gender equality is the elimination of all forms of discrimination based on gender so that girls and women, boys and men have equal opportunities and benefits while gender equity means giving equal treatment to both girls and boys, women and men to access resources and opportunities. In the enclaves of education it refers to ensuring that girls and boys have equal access to enrolment and other educational opportunities. Gender responsiveness means recognizing the needs and peculiarities of each gender and meeting such needs with all human dignity and integrity. For instance both women and men need to be treated with respect, given fair hearing, appreciated and so on. This will mean that in a gathering where a public address is to be made, a public address system should be made available so that both women and men will be head by the audience. A situation where a woman is being hooted at to shout so that the audience could hear should not arise. Being gender responsive at this instance means recognizing that the male voice is louder than the female voice, therefore something that could boost her voice is made available. When the society is gender responsive they stand to benefit fully from the contributions of both sexes to social development. Gender responsiveness means giving equal treatment and opportunities to both sexes based on their inherent differences. It is the basic requirement for gender compatibility [14].

\section{Importance of gender compatibility}

a) Gender compatibility creates the awareness that the synergic contributions of both genders are needed for the survival and development of every society.

b) It creates the awareness that the opposite gender is equally as competent, versatile and relevant as one's own and should not be discriminated against. 
c) It helps people to accept their gender without feeling inferior or incapacitated. Both genders will have a sense of commitment towards a functional and developed society for the good of all.

d) Gender compatibility brings about the recognition of the inherent difference in gender as a needed compliment for mutual existence and societal development. This means that no one gender is independent of itself or sufficient without the other but rather females and males appreciate their natural differences and symbiotically function in the society, one complimenting the other to bring about the total essence of human existence. This will break the walls of gender roles, duties and responsibilities will not affixed to any particular gender but will be taken by any one (female or male) based on competence and availability.

e) It will make the males to relate duly to the females on their merit and honor. This will provide a leveled ground for social development. When females are not given adequate support to perform they withdraw and the stand to lose their contribution [15].

\section{Recommendation}

a) Gender stereotypes should be erased from people's minds because they are defamatory.

b) Individuals, irrespective of their gender should be allowed to play roles according to their natural abilities, talents and callings, since no gender is superior to the other. This mean that responsibilities and roles should be done by anyone who does it better and is available.

c) Everyone should be gender contented. No one should feel he/she could have been better off in the opposite gender. No gender incapacitates or enables. Contentedness builds self esteem which is required for self realization.

\section{Social Development and Gender Compatibility}

The development of a society is linked to the well-being of its citizens. Hence Social development is about improving the well-being of every individual in the society so they can reach their full potential. To achieve this, all forms of gender bias and discrimination have to be put aside. The wellbeing of females as well as the males is to be improved equally otherwise if one sex is preferred and favored against the other, the neglected sex could be a clog in the will of progress. Of course development cannot be seen as having taken place when only one sex is attended to and the other neglected. Gender equality and equity is a vital aspect to social development so that both females and males will be equally well fared to reach their full potentials. Social development also has to do with the way the people interact in groups and the norms that facilitate such interactions shape the processes of development. People need to be gender responsive in their gender relations. Gender relations refer to relationships between women and men acquired through the process of socialization in terms of power sharing, decision - making, and division of labor within the household and in the society at large Mlama et al. [2]. This implies that individuals treat each other fairly in their daily lives, whether in the family, workplace, or in public places. Females and males should have the right to hear and be heard and this includes participation at all levels of leadership, trade and investments. Social development requires the removal of barriers so that all citizens can attain the peak of their potentials. Such barriers are those posed by gender roles and stereotypes. Whatever amenity or opportunity is good for one gender is also good for the other. Denial done to either will lead to a setback in the development of the society $[16,17]$.

\section{Implications}

The implications of the paper are that:

a) Gender roles are socially constructed and subject to change therefore should not be held sacrosanct. Anybody (male or female) can fit into any social role.

b) Gender stereotypes are derogatory and antisocial, this could kill talents, encourage indiscipline, oppression, self conceit and arrogance. These are some of the factors that could suppress good living conditions which are against social development.

c) Gender compatibility will ensure complimentary and harmonious existence by taking away social imbalance and disparities. This atmosphere will breed social development and its attendant benefits to the people.

d) A gender responsive society treats people with dignity, irrespective of their gender. They will then confidently develop their skills and talents to benefit the society.

e) Attributing assertiveness to males generates indiscipline and other delinquent tendencies among them which is a minus to social development. While it encourages indolence among females who hitherto would have been very productive.

f) Ensuring gender compatibility will mean hat relationships will improve and social well being will increase as investment on people will no longer be based on their gender.

\section{Summary}

Sex is a biological characteristic of an individual e.g. male and female while gender refers to the socially constructed roles, activities and responsibilities attributed to particular sex e.g. masculine and feminine. No gender is superior or inferior to the other therefore all forms of discrimination should be replaced with equality and equity, while the entire society should be gender responsive. It has been explained that the female and male exist to function symbiotically for their optimal benefit, no one gender is by itself independent or sufficient without the other. Being a female is noble just like being a male, it is strength not vulnerability or weakness. There has to be a synergy in the combination of their efforts and resources. This symbiotic 


\section{Psychology and Behavioral Science International Journal}

relationship is what is referred as gender compatibility and it is required for social development.

\section{References}

1. Ibe HN (2017) Gender and issues in curriculum implementation. In Nzewi UN, Kanno TN, Obasi VA, Obih SOA (eds). New Perspectives in gender studies in Nigeria, Mercy Divine Publishers, Owerri, Nigeria.

2. Mlama P, Dioum M, Makoye H, Murage L, Waga M, et al. (2005) Gender responsive pedagogy: A teacher's handbook. Nairobi, Kenya.

3. Kanno TN, Ijioma BC, Obih SOA (2017) Gender stereotypes and indiscipline: an over view. In Nzewi, UN, Kanno TN, Obasi VA, Obih SOA (eds). New Perspectives in gender studies in Nigeria, Mercy Divine Publishers, Owerri, Nigeria.

4. Merriam G, Merriam C (1831) Merriam Webster's online dictionary.

5. Bloom BE, Covington SS (2001) Effective gender responsive intervention in juvenile justice.

6. Nobelius AM (2004) What is the difference between sex and gender?

7. Oberle E, Schonert-Reichl KA, Thomson KC (2010) Understanding the link between social and emotional well-being and peer relations in early adolescence: Genderspecific predictors of peer acceptance. Journal of Youth and Adolescence 39(11): 1330-1342.

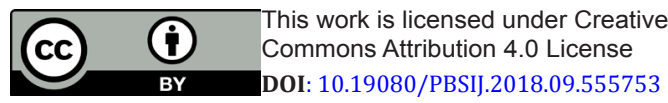

8. Young R, Sweeting H (2004) Adolescent bullying, relationships, psychological well-being, and gender-atypical behavior: A gender diagnosticity approach. Sex Roles 50: 525-537.

9. Eagly AH, Karau SJ (1991) Gender and the emergence of leaders: A metaanalysis. Journal of Personality and Social Psychology 60(5): 685710 .

10. Petersen SM (2015) How Gender Typicality Moderates the Relation between Preadolescents' Empathy and Acceptance. A Thesis Presented in Partial Fulfillment of the Requirements for the degree Master of Family \& Human Development.

11. Jewell JA, Brown CS (2013) Relations among gender typicality, peer relations, and mental health during early adolescence. Social Development 23(1): 137-156.

12. Carver PR, Yunger JL, Perry DG (2003) Gender identity and adjustment in middle childhood. Sex Roles 49: 95-109.

13. Russell S, Kosciw J, Horn S, Saewyc E (2010) Safe schools policy for LGBTQ students. Social Policy Report 24: 1-25.

14. GLAAD media reference guide - transgender issues.

15. Indices of Social Development Defining.

16. What is social development?

17. World Health Organisation in Gender, equity, and human rights.

\section{Your next submission with Juniper Publishers} will reach you the below assets

- Quality Editorial service

- Swift Peer Review

- Reprints availability

- E-prints Service

- Manuscript Podcast for convenient understanding

- Global attainment for your research

- Manuscript accessibility in different formats ( Pdf, E-pub, Full Text, Audio)

- Unceasing customer service

Track the below URL for one-step submission https://juniperpublishers.com/online-submission.php 